\title{
Finite element analysis of composite cylinder with centre cutout under axial load and internal pressure
}

\begin{abstract}
Results from Finite Element (FE) study on the response of composite cylinder shells with cutouts and subjected to internal pressure and axial compression are presented. The objective of the study is to improving the buckling load by applying the internal pressure whilst the compression load is applied. The effect of localized stress concentration distributed around the cutout region also being examined. The numerical results are obtained using ABAQUS finite element code software package. The composite cylinder shells were tested in two conditions which are a combination of axial compression load with internal pressure and a single axial compression load. The effects of varying internal pressure and cutout size on the pre-buckling, buckling, and post-buckling responses of the shell are demonstrated. Reasonable results comparison was obtained by reviewing previous literature. Results indicated that the load distribution and displacement of the cutout significantly influence the structural response of the shell. The results also indicate that the stress distributions can be affected by the size of the cutout under axial compression load.
\end{abstract}

Keyword: Composite shell; Finite element method; Cylinder cutout buckling stress 